\title{
Simplified Template Preparation and Improved Direct Sequencing Using Taq Polymerase
}

\author{
Anand K. Srivastava, Vittorio Montanaro, and Juha Kere \\ Department of Molecular Microbiology and Center for Genetics in Medicine, \\ Washington University School of Medicine, St. Louis, Missouri 63110
}

A streamlined version of direct dideoxy sequencing is presented that includes template preparation as well as sequencing protocols. The method is used routinely to sequence double-stranded PCR products after minimal purification with one of the primers used in amplification. Either ${ }^{35} \mathrm{~s}$ or $32 \mathrm{p}$ labeling can be used with equally good results.
$\mathbf{T}$ he polymerase chain reaction (PCR) has provided an effective way to bypass subcloning steps in the preparation of templates and sequencing.(1) We have applied an amplificationdriven sequencing procedure (a combination of PCR-based template preparation and direct temperature-cycled sequencing) to a variety of tasks (see below) including direct sequencing of double-stranded PCR products.

The methods described here are highly dependable when rapid sequencing of large numbers of templates is needed. The advantages of this protocol over previously published methods of direct sequencing include: (1) simple template preparation (see below) with minimal manipulation of the sequencing template (tiny quantities of template DNA present in agarose are sufficient, and further DNA purification is not required); (2) efficacy with both double-stranded and single-stranded templates; (3) routine application, with either primer used for the template preparation or with an internal primer; and (4) use of either ${ }^{35} \mathrm{~S}$ or ${ }^{32} \mathrm{P}$ as label. The quality of the gels is high enough (with less background) to read up to 300 nucleotides in a single run. Even longer sequences can be read by double loading.

\section{METHODS}

Genomic or cloned DNA is amplified in a thermal cycler (Perkin-Elmer Cetus), typically for $30-35$ cycles at $94^{\circ} \mathrm{C}$ for $1 \mathrm{~min}, 55-65^{\circ} \mathrm{C}$ for $2 \mathrm{~min}$, and $72^{\circ} \mathrm{C}$ for $2 \mathrm{~min}$ in a reaction volume of $25 \mu$ l containing TNK 50 buffer (10 mM Tris- $\mathrm{HCl}, \mathrm{pH} 8.6,50 \mathrm{~mm}$
$\mathrm{KCl}, 1.5 \mathrm{mM} \mathrm{MgCl}_{2}, 5 \mathrm{mM} \mathrm{NH} \mathrm{NH}_{4} \mathrm{Cl}$; Nowotny et al., pers. comm.), 10 pmoles of each primer, $100 \mu \mathrm{M}$ dNTPs, and 0.5 units of AmpliTaq (PerkinElmer Cetus). The reaction products are separated in $1 \%$ agarose gels (SeaPlaque), and a piece of agarose containing the specific product to be sequenced is excised and melted before adding directly to sequencing reactions (gel pieces can also be stored at $4^{\circ} \mathrm{C}$ ). (In some problem cases, reamplification and excision from agarose gel or high-resolution separation of the specific band on $6-8 \%$, wt/vol, polyacrylamide/bisacrylamide gels help to reduce background. DNA is recoverd by electroelution, and then it is phenol: chloroform extracted once, or extracted in $0.5 \mathrm{M}$ ammonium acetate $/ 1$ mM EDTA from a piece of the gel, precipitated with ethanol, and suspended in $15 \mu \mathrm{l}$ of $10 \mathrm{~mm}$ Tris- $\mathrm{HCl}, 1 \mathrm{~mm}$ EDTA, pH 8.0.) Reaction conditions for preparing PCR products can be varied depending on the primers. In our hands, varying $\mathrm{KCl}$ concentration from 25 to $100 \mathrm{~mm}$ covers most of the primer pairs tested.

Two variations of the basic sequencing reactions have been used to label sequencing products. In one approach, unlabeled sequencing primer ( 0.5 pmole per $\mathrm{mix}$ ) is used with either $\left[\alpha-{ }^{35} S\right]$ dATP or $\left[\alpha-{ }^{32} \mathrm{P}\right] \mathrm{dATP}$ in the sequencing reaction. Labeled $\mathrm{dCTP}$ can be substituted for labeled dATP. Alternatively, 5 pmoles of sequencing primer is kinase labeled at its $5^{\prime}$ end with $\left[\gamma^{32}{ }^{32} \mathrm{P}\right] \mathrm{ATP}^{(2)}$; and one-tenth of the end-labeling reaction mix is added to the mix without any purification 
(see below). In at least some cases, $\alpha$ labeled nucleotide provided more uniformity of signal strength across the gel. Presumably, the method could be adapted to fluorescence-based sequencing. (3)

A sequencing $\mathrm{mix}$ is prepared in a final volume of $36 \mu$ l containing $8 \mu \mathrm{l}$ 5x TNK 50 buffer, $4.5 \mu \mathrm{l}$ dNTPs $(25 \mu \mathrm{M}$ each), 1.0 unit of AmpliTaq, and 100-200 ng of template in agarose or suspended in $10 \mathrm{mM}$ Tris- $\mathrm{HCl}, 1 \mathrm{~mm}$ EDTA, pH 8.0, 0.5 pmole of unlabeled primer with $\left[\alpha_{-}{ }^{35}\right.$ S]dATP $(7.5-15 \mu \mathrm{Ci}$ of $1 \mathrm{mCi} /$ nmole sol., Amersham) or [ $\alpha$ 32P]dATP $(2 \mu \mathrm{Ci}$ of $3 \mathrm{mCi} / \mathrm{nmole}$ sol., Amersham) or 0.5 pmole of endlabeled sequencing primer. (With unlabeled sequencing primers, template DNA should be free of any contaminating primers or oligonucleotides.) Ninemicroliter portions of the reaction mix are added to each four tubes (marked $\mathrm{G}, \mathrm{A}, \mathrm{T}$, and $\mathrm{C}$ ) containing $1 \mu \mathrm{l}$ of 0.25 mM ddGTP, $2.5 \mathrm{mM}$ ddATP, $5.0 \mathrm{~mm}$ ddTTP, or $2.5 \mathrm{mM}$ ddCTP, respectively. Each reaction mix is overlaid with 20-30 $\mu \mathrm{l}$ mineral oil, and sequencing cycling is performed for $15-25$ rounds, in the same conditions used for template preparation (see above). Four microliters of stop solution ( $95 \%$ formamide, $0.1 \%$ xylene cyanol, $0.1 \%$ bromophenol blue) is added at the termination of reaction, and the content is heated at $75^{\circ} \mathrm{C}$ for $4 \mathrm{~min}$ before loading 3-4 $\mu \mathrm{l}$ of each reaction mix on a $6 \%(\mathrm{wt} / \mathrm{vol})$ polyacrylamide-urea or a $5 \%$ (vol/vol) Hydrolink (AT Biochemicals)-urea sequencing gel. The autoradiograms are exposed at room temperature without an intensifying screen. If pauses or stops are encountered, they can usually be overcome by elevating the annealing temperature in the sequencing protocol or by using $10 \%$ DMSO in the sequencing reaction.

\section{RESULTS AND CONCLUSIONS}

Typical results are shown in Figure 1. All 20 different sequencing primers used thus far have yielded useful sequence.

We have successfully used this procedure in the analysis of Alu-PCR products, ${ }^{(4)}$ determination of terminal sequences of inserts in yeast artificial chromosomes (YACs) for chromosomal walking, ${ }^{(5)}$ design of sequence tagged

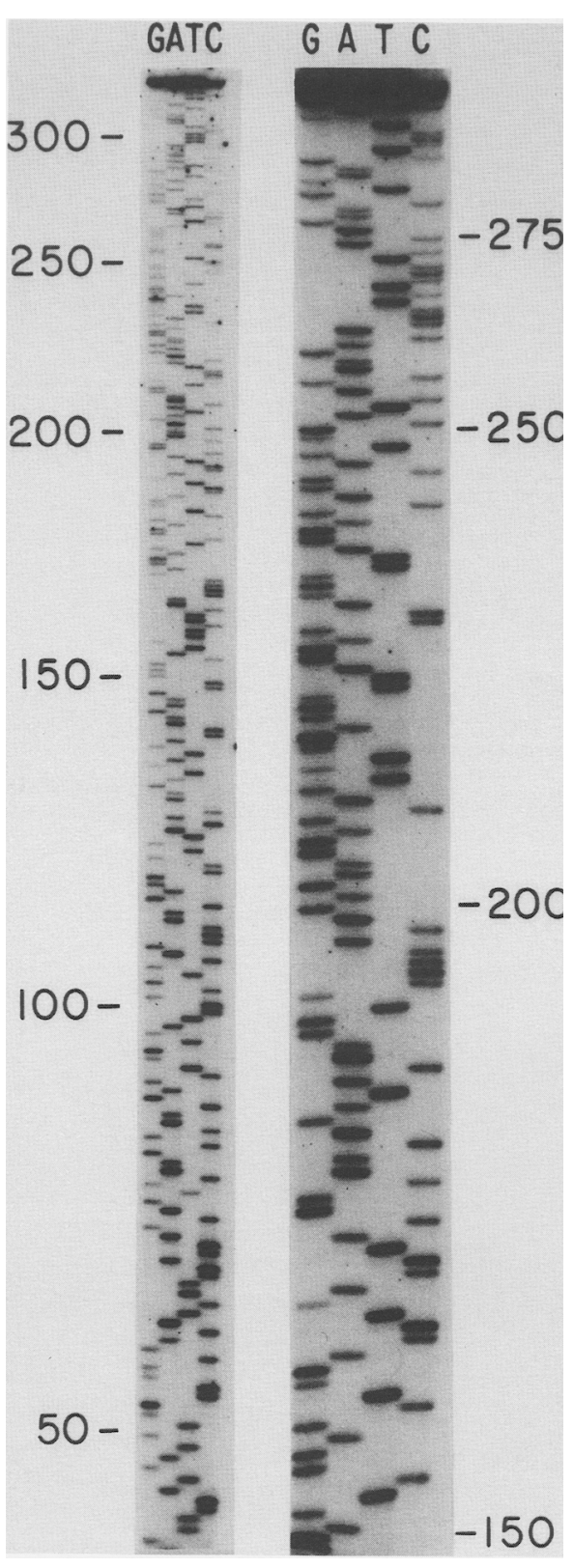

FICURE 1 Full-length view of a sequencing autoradiogram obtained using a 20-mer oligo-primer and $\left[\alpha_{-}{ }^{35}\right.$ S $]$ dATP. The gel was fixed in $10 \%$ methanol/acetic acid solution, dried, and exposed for $14 \mathrm{hr}$ at room temperature (left panel). (Right panel) Upper portion of a sequencing autoradiogram obtained using a ${ }^{32} \mathrm{P}$ kinase-labeled oligoprimer (20 nucleotides) specific for the glucose-6-phosphate-dehydrogenase gene. The gel was exposed for $3 \mathrm{hr}$ at room temperature.

sites (STSs, ${ }^{(6)}$ ) comparison of homologous regions from different species (Mazzarella et al., in prep.) and detection of point mutations.

Simple and generalized template preparation with direct sequencing of double-stranded PCR products makes this procedure rapid without any loss in gel quality as compared to other methods using Sequenase or Taq polymerase.

\section{ACKNOWLEDGMENTS}

We thank Dr. David Schlessinger for his valuable suggestions and support. TNK buffer was developed by Dr. Volker Nowotny at the Center for Genetics in Medicine, Washington University. We also thank Dr. Yuko Kazano for sharing her experiences and members of laboratory for discussion and stimulation. This research was supported by National Science Foundation grant DMB 9005473 and National Institutes of Health grant HG 00247.

\section{REFERENCES}

1. Ruano, G. and K.K. Kidd. 1991. Coupled amplification and sequencing of genomic DNA. Proc. Natl. Acad. Sci. 88: 2815-2819.

2. Murray, V. 1989. Improved doublestranded DNA sequencing using the linear polymerase chain reaction. Nucleic Acids Res. 17: 8889.

3. Wilson, R.K., C. Chen, N. Avdalovic, J. Burns, and L. Hood. 1990. Development of an auto-mated procedure for fluorescent DNA sequencing. Genomics 6: 626-634.

4. Nelson, D.L., S.A. Ledbetter, L. Corbo, M.F. Victoria, R. Ramírez-Solis, T.D. Webster, D.H. Ledbetter, and C.T. Caskey. 1989. Alu polymerase chain reaction: A method for rapid isolation of human-specific sequences from complex DNA sources. Proc. Natl. Acad. Sci. 86: 6686-6690.

5. Mueller, P.R. and B. Wold. 1989. In vivo footprinting of a muscle specific enhancer by ligation mediated PCR. Science 246: 780- 786.

6. Olson, M.V., L. Hood, C. Cantor, and D. Botstein. 1989. A common language for physical mapping of the human genome. Science 245: 14341435.

Received December 12, 1991; accepted February 4, 1992. 